\title{
Magnetized Water and Memory Meter
}

\author{
Ashraf Kotb \\ Department of Mechanical Power Engineering, Faculty of Engineering, Ain Shams University, Cairo, Egypt \\ Email: Ashraf_Ibrahim@eng.asu.edu.eg
}

Received May 12, 2013; revised June 12, 2013; accepted June 19, 2013

Copyright (C) 2013 Ashraf Kotb. This is an open access article distributed under the Creative Commons Attribution License, which permits unrestricted use, distribution, and reproduction in any medium, provided the original work is properly cited.

\begin{abstract}
This paper presents an experimental study to investigate the effect of using the magnetic water conditioner on the properties of water. The water flows through a closed loop, while the $\mathrm{pH}$, TDS, and hardness represent its properties. For magnetic water conditioner with flux density of $170 \mathrm{mT}$, results showed that $\mathrm{pH}$ increased by $15.65 \%$ for 820 minutes of non-stop circulation. The increase in $\mathrm{pH}$ is divided to $93.5 \%$ for the first 360 minutes, and $6.5 \%$ for the last $460 \mathrm{~min}-$ utes. TDS and Hardness of water are not affected by the magnetic water conditioner. Water remembers and keeps the impact of passing through the magnetic field for several hours, and $\mathrm{pH}$ decreased by 0.642 in 24 hours. While the results lead to introduce and create the magnetized water saturation curve and water memory meter.
\end{abstract}

Keywords: Magnetic; Water; pH; TDS; Hardness; Memory; Saturation; Meter

\section{Introduction}

Much time has passed since the discovery of the effect of magnetic water treatment by Vermeiren [1]. Having begun with a decrease in the formation of scale in steam boilers, the magnetic treatment of water and aqueous systems has found wide application in recent years in the most varied fields of practical human activity, since the overwhelming majority of energetic and industrial processes are connected with water. Magnetic treatment is presently used in combating precipitation, in the production of concrete, and in the enrichment of useful minerals, as well as for the intensification of water filtration and purification processes, etc.

Magnetic water conditioners are permanent magnets that attach to waterlines entering to "purify" or "condition" water supplies. These devices purportedly use magnetic fields to change the molecular makeup of various water constituents like calcium and iron to other more "inert" forms. The claimed result is a reduction or elimination of water contaminants.

There is virtually no valid scientific data to support any water treatment benefit from magnetic devices. Despite this, companies, sales representatives, and product brochures for the devices may make any one of the many claims [2].

Usually, printed testimonials from "hundreds of satisfied customers" support these claims. The claims put forth by manufacturers and sales representatives of these devices are without validity. They do not refer to standard physical, chemical, or biological water treatment processes. Therefore, several researchers have conducted performance evaluations of the equipment.

The researchers are divided into two sides; the first side opposes using the magnetic water conditioners, while the second side supports the benefits of the usage of magnetic water conditioners.

As early as 1977, Duffy [3] concluded that permanent magnets have no effect on the hardness of water or the formation of scales on pipes. The South Dakota School of Mines and Technology performed tests on several magnetic conditioners units. Researchers concluded that there was no change in the physical and chemical properties or the calcium ion concentration of water conditioned with the devices [4]. A third study conducted in 1985 at Purdue University tested six units placed on water supplies for water heaters and tested their effectiveness against a controlled system. Water was tested for temperature, specific conductivity, surface tension, boiling point of depression, $\mathrm{pH}$, alkalinity, total hardness, calcium and scaling effect. The study concluded that no significant variation in the chemical water quality existed between the control and the "treated" systems.

The U.S. Army Corps of Engineers [5] tested three devices and the results showed that no clear advantage for any of the three devices tested versus a control for the inhibition of mineral scale formation or the corrosion of copper. 
A study conducted in 2013 at Ain Shams University tested five units placed on PP-R pipe line for open loop water flow and tested their effectiveness. Water was tested for $\mathrm{pH}$, hardness, and total dissolved solids. The study concluded that no significant variation in the chemical water quality existed from the units [6].

On the other side, Banejad and Abdosalehi [7] showed that the magnetic field affected on water quality and that production of magnetic water has ability on water hardness reducing until 51 percent.

Rameen et al. [8] reported the effect of commercial magnetic water conditioners on the total dissolved salts and $\mathrm{pH}$ on different solutions, the work includes laboratory evidence of water quality modifications which supplies different purposes using magnetic means.

Ghauri and Ansari [9] reported the effect of magnetic field on the water viscosity between 298 and $323 \mathrm{~K}$. A higher absolute viscosity has been observed in the presence of applied magnetic field compared to no field which has been explained on the basis of stronger hydrogen bonds.

Szcze et al. [2] found that the magnetic field decreases the water conductivity, which is inversely proportional to the flow rate, and increases the amount of evaporated water, even after the water's distillation. The effects are due to the hydrogen bond network strengthening and the perturbation of gas/liquid interface from the air nanobubbles in the water.

Also, many testimonials are uploaded in each manufacturer site to certify the effectiveness of magnetic water conditioners

The objective of the present work is to investigate experimentally for water flows in closed loop and, the effect of magnetic water conditioner on $\mathrm{pH}$, TDS, and Hardness of water. Also, the objective extends to demonstrating the effect of time on the properties of magnetically conditioned water.

\section{Materials and Methods}

According to [5], the test rig is constructed from nonmetallic piping, fittings, and pump to avoid increase in the turbidity of flowing water. The test rig is illustrated in Figure 1, it contains 4 liter glass tank, while PVC pump draws water from the tank via a plastic hose and discharges through a plastic hose followed by polypropylene PP-R pipe, the pipe is fitted with gate valve, the discharged water is recirculated into the tank through plastic hose. The test rig performs a closed loop of circulation, while the magnetic water conditioner (MWC) is placed before the valve and over the PP-R pipe. The magnetic water conditioner is investigated with the specifications listed in Table $\mathbf{1}$ and installation as shown in Figure 2.

Instrumentation system is chosen to measure the $\mathrm{pH}$, total dissolved solids, hardness values, and magnetic

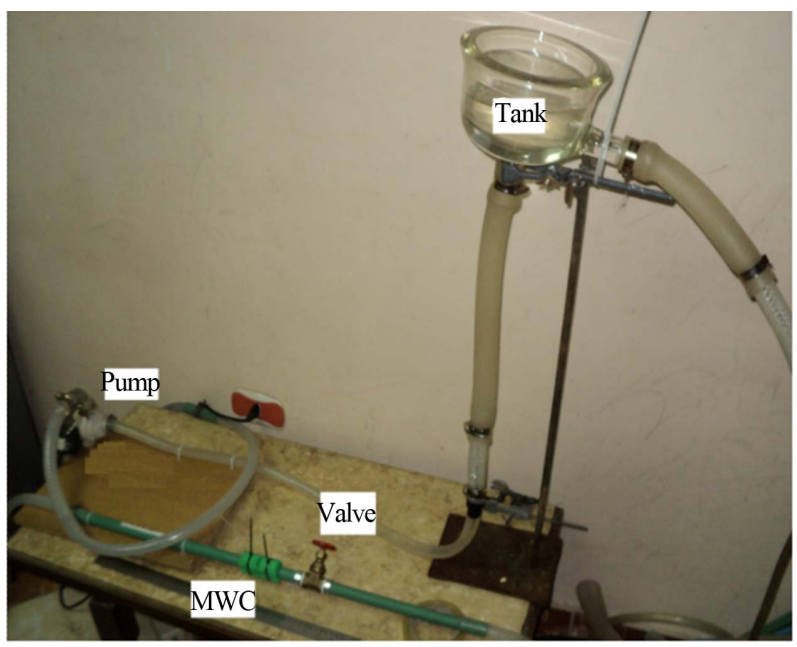

Figure 1. Components and Construction of Test Rig.

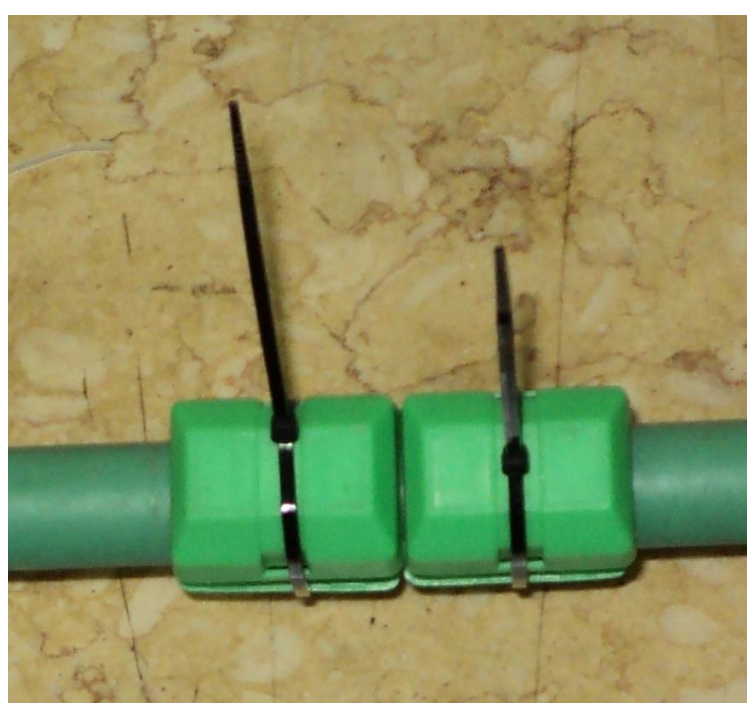

Figure 2. Installation of MWC-01 on Test Rig.

Table 1. Specifications and Installation of MWC.

\begin{tabular}{cc}
\hline Brand & $\begin{array}{c}\text { Specifications and Installation } \\
\text { Ultra Power Magnetic Water Softener UP-2 } \\
2 \text { pairs in one set } \\
\text { Description per Manufacturer: } \\
\text { Assembled with strong NdFeB magnet part } \\
\text { Powermag } \\
\text { China }\end{array} \quad \begin{array}{c}\text { exchange water molecule and mineral hydronium, } \\
\text { makes } \mathrm{Ca}^{2+} / \mathrm{Mg}^{2+} \text { to unite electro, and has no } \\
\text { cation function temporarily. Hence, even heating, } \\
\text { it doesn't unite hydronium-for example } \mathrm{SO}_{4}^{2-} \\
\text { The part makes water not to scale any more. } \\
\text { Magnetic filter makes water soft, and scale will } \\
\text { be never produced in water pipe. }\end{array}$ \\
\hline
\end{tabular}

field intensity. $\mathrm{pH}$ is measured by high accuracy pen type $\mathrm{pH}$ meter with accuracy of \pm 0.1 and resolution of 0.01 . TDS is measured by TDS meter with range from 0 to $1999 \mathrm{ppm}$ and accuracy of $\pm 2 \%$ f.s. Hardness is deter- 
mined by EDTA titration method. The magnetic flux density is measured by Gauss/Tesla meter with zero flux chamber.

Regarding to the chemical analysis to determine the hardness of samples, titration procedures provide relatively inexpensive means for the analysis of different substances. These titrations are based on chemical reactions with completion points that can be monitored by some visible change in the reaction systems. The most common system involves acids and bases with the use of an indicator that changes color as the system moves from an acidic to basic composition. Calcium and magnesium ions can be measured through reaction with a chelating agent EDTA (ethylenediaminetetraacetic acid). This molecule has four carboxylic acid $(\sim \mathrm{COOH})$ group sites and two nitrogens, all of which have lone pairs of electrons. The EDTA molecule can form a complex with as many as six sites on a particular cation like $\mathrm{Ca}^{2+}$. These EDTA complexes are generally very stable are always in 1:1 (metal:EDTA) molar ratios:

In this activity we will be titrating $\mathrm{Ca}^{2+}$ in water samples with EDTA. Both $\mathrm{Ca}^{2+}$ solutions and EDTA are colorless so an indicator is needed to signal the reaction completion. The indicator of choice is Eriochrome Black $\mathrm{T}$ which forms a wine-red complex with $\mathrm{Mg}^{2+}$. A very small amount $\mathrm{Mg}^{2+}$ will be bound to the indicator through most of the titration. When all of the $\mathrm{Ca}^{2+}$ has reacted with EDTA, the $\mathrm{Mg}^{2+}$ in the indicator will react with the EDTA. The Indicator then returns to its acidic form which is a sky-blue and signals the end of the process. Below are the reactions that occur during the titration where $\mathrm{H}_{3} \mathrm{In}$ is the general formula for the Eriochrome Black T.

$$
\begin{array}{ll}
\text { During titration: } & \mathrm{H}_{2} \mathrm{Y}^{2-}(\mathrm{aq})+\mathrm{Ca}^{2+}(\mathrm{aq}) \rightarrow \mathrm{CaY}^{2-}(\mathrm{aq})+2 \mathrm{H}^{+}(\mathrm{aq}) \\
& \mathrm{H}_{2} \mathrm{Y}^{2-}(\mathrm{aq})+\mathrm{Mg}^{2+}(\mathrm{aq}) \rightarrow \mathrm{MgY}^{2-}(\mathrm{aq})+2 \mathrm{H}^{+}(\mathrm{aq}) \\
\text { At end point } & \mathrm{H}_{2} \mathrm{Y}^{2-}(\mathrm{aq})+\mathrm{MgIn}^{-}(\mathrm{aq}) \rightarrow \mathrm{MgY}^{2-}(\mathrm{aq})+\mathrm{HIn}^{2-}(\mathrm{aq})+\mathrm{H}^{+}
\end{array}
$$

$$
\text { Wine-red sky-blue }
$$

\section{Results and Discussion}

The manufacturer of the used magnetic water conditioner wrote the technical specifications and benefits of using the magnetic water conditioner, but there are no scientific or measured data about the construction, material, and the magnetic flux density. For this reason and before investigating the effect of magnetic water conditioner, an attempt is carried out to measure the magnetic flux density for the used magnetic water conditioner. The magnetic flux density is measured at the contact surface for each piece; it was found that the flux density is not uniformly distributed over the contact surface with the maximum of $330.0 \mathrm{mT}$. After installation the magnetic flux density inside the pipe is measured, it was found that the flux density is not uniformly distributed over the cross flow area or the covered length with the maximum of $170.0 \mathrm{mT}$.

The test rig is filled with water; initially, amount of Sodium Chloride is dissolved in the water to raise the total dissolved solids in the water, and $\mathrm{pH}$, TDS, and Hardness are measured and considered to be the base line data for the water properties before recirculated through the magnetic water conditioner.

Unified method of measurements is performed throughout the work; each water sample at each time is measured and chemically analyzed 10 times, the values are statistically analyzed and the mathematical average represents as the result at the time.
Figure 3 illustrates the $\mathrm{pH}$ values of recirculated water versus the time of circulation, before circulation the base line data is clearly identified to be 7.343. The $\mathrm{pH}$ is increased by increasing the circulation time; over 820 minutes of non-stop circulation the $\mathrm{pH}$ reaches 8.492 with total increase of $1.149 \%$ with $15.65 \%$.

One can explain the result as; when water flows through the magnetic field, the nuclei of its atoms are polarized, this polarization makes the atoms behave as tiny magnets with north and south poles. The net results are; increment in the $\mathrm{pH}$ value as a result of polarization and uniform arrangement of atoms as a result of the creating poles. Increasing the circulation time increases the residence time at which water is subjected to the magnetic field, which gives the atoms enough time for more polarization and more uniformity in the arrangement of atoms.

The $\mathrm{pH}$ increases 1.074 during the first initial 360 minutes of circulation, this increment represents $93.5 \%$ from the total increase achieved. While the $\mathrm{pH}$ increases 0.075 during the last 460 minutes of circulation, this increment represents $6.5 \%$ from the total increase achieved.

One can say that; the first 360 minutes of circulation divided the behavior of $\mathrm{pH}$ into two sections; the first section is from 0 to 360 minutes at which the $\mathrm{pH}$ increases with noticeable values, the second section is from 360 to 820 minutes at which the $\mathrm{pH}$ increases with very small values. This phenomenon needs to define the term (Saturation Time) and it may be defined as; the circula- 
tion time through the magnetic water conditioner for maximum increase in the $\mathrm{pH}$ value. Consequently, for the circulation time less than the saturation time one can define that the water is in the state of sub-saturation, while for circulation times greater than the saturation time the water is the saturation as illustrated in Figure 4 which is defined as the Magnetized Water Saturation Curve.

Figure 5 illustrates the TDS values of recirculated water versus the time of circulation, before circulation the base line data is clearly identified to be $1219.9 \mathrm{ppm}$. It is deduced that; over the 820 minutes of circulation through the magnetic water conditioner, the TDS of water does not affected by recirculation through the magnetic water conditioner. The averages of measured values at each time are in the range of uncertainty.

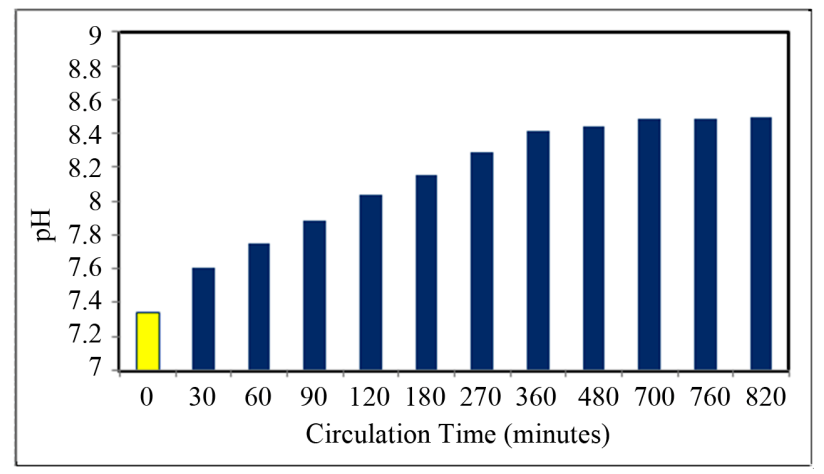

Figure 3. pH of Circulated Water.

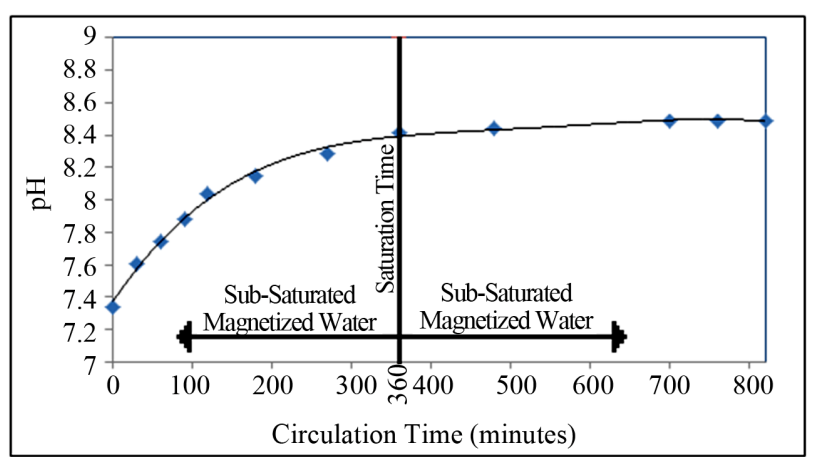

Figure 4. Magnetized Water Saturation Curve.

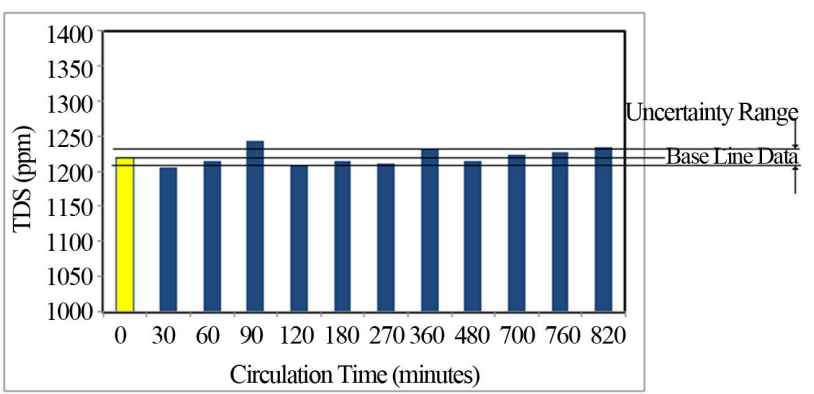

Figure 5. TDS of Circulated Water.
Figure 6 illustrates the Hardness values of recirculated water versus the time of circulation, before circulation the base line data is clearly identified to be $139.5 \mathrm{ppm}$. It is deduced that; over the 820 minutes of circulation through the magnetic water conditioner, the Hardness of water does not affected by recirculation through the magnetic water conditioner. The averages of measured values at each time are in the range of uncertainty.

Since the previous results showed that; the effect of the magnetic water conditioner is dominated on increaseing the $\mathrm{pH}$ of circulating water from 7.343 to 8.492. Therefore, the question arises here, is to what time the water keep the maximum value of $\mathrm{pH}$ of 8.492 , which is obtained from the flowing through the magnetic water conditioner for 820 minutes, after it being stored in static condition and away from the magnetic water conditioner. This question illustrates the effect of magnetic water conditioner on the memory of magnetized water.

The answer of the last question extends the present work herein; an amount of water with $\mathrm{pH}$ of 8.492, after 820 minutes of recirculation through the magnetic water conditioner is stored and isolated from atmospheric air to eliminate the effect of absorption of atmospheric gases by the stored water. The time counter is restarting, and after periods of time, a sample is taken from the stored water and the $\mathrm{pH}$ value is measured by taking as mentioned 10 measurements each time. The total storage objective time is 24 hours; Figure 7 illustrates the $\mathrm{pH}$ values of stored water versus the time. As illustrated the

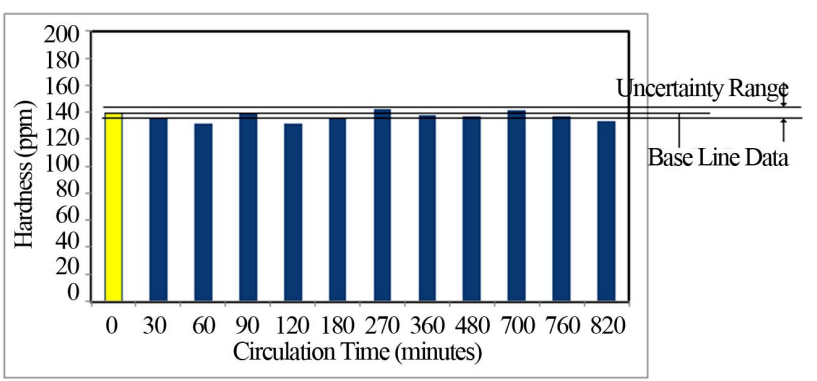

Figure 6. Hardness of Circulated Water.

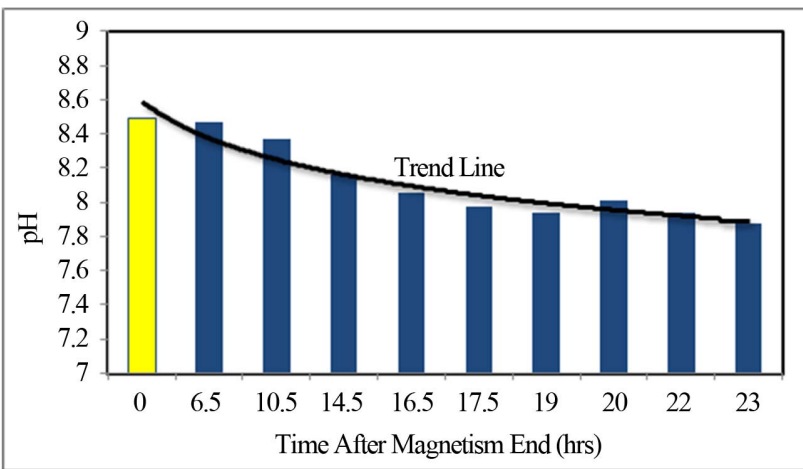

Figure 7. pH of Magnetized Water (Memory of Water). 
water remember and keep the impact of passing through the magnetic field, it is declared as keeping high $\mathrm{pH}$ values 8.466 after 6.5 hours, and the water memory continue to forget the magnetic impact to be with $\mathrm{pH}$ of 7.88 over the 24 hours. One can deduce that; for $1.149 \mathrm{pH}$ increase in 820 minutes, the $\mathrm{pH}$ decreases 0.642 in 24 hours.

This phenomenon needs to define the term (Water Memory) and it may be defined as; the time at which the magnetized water remember the impact of magnetic field. The $\mathrm{pH}$ value may be considered as the (Water Memory Meter).

\section{Conclusion and Recommendations for Future Work}

It is concluded that, for water recirculated in closed loop through the $170 \mathrm{mT}$ applicable magnetic water conditioner:

1) $\mathrm{pH}$ is increased by $15.65 \%$ over 820 minutes of non-stop circulation.

2) $\mathrm{pH}$ is increased by $93.5 \%$ over the first 360 minutes, and $6.5 \%$ over the last 460 minutes.

3) TDS and Hardness of recirculated water are not affected by the circulation through the magnetic water conditioner.

4) Water remembers and keeps the impact of passing through the magnetic field for several hours, the $\mathrm{pH}$ decreases 0.642 in 24 hours.

Also, two phenomenons are introduced and definitions are created;

1) The magnetized water saturation curve; which governs the behavior of water during magnetism.

2) The water has a memory with $\mathrm{pH}$ as water memory meter.

The proposed work focuses many future research points; the dependence of magnetized water saturation curve and water memory meter, the water content of total dissolved solids, temperature of water, initial $\mathrm{pH}$ value, magnetic flux density and shape of the magnetic water conditioner, water flow velocity, and quantity of recirculated water. And the research points may be extended to different fluids.

\section{REFERENCES}

[1] T. Vermeiren, "Magnetic Treatment of Liquids for Scale and Corrosion Prevention," Anti-Corrosion Methods and Materials, Vol. 5, No. 7, 1958, pp. 215-219. doi:10.1108/eb019464

[2] A. Szcze, E. Chibowskia, L. Hołysza and P. Rafalski "Effects of Static Magnetic Field on Water at Kinetic Condition," Process Intensification, Vol. 50, No. 1, 2011, pp. 124-127.

[3] E. A. Duffy, "Investigation of Magnetic Water Treatment Devices," Doctorate Thesis, Clemson University, Clemson, 1977.

[4] C. E. Gruber and D. D. Carda, "Measurable Parameters in Water Conditioning Equipment as Determined in Laboratory Simulations at Rapid City, South Dakota," 1981.

[5] Public Works Technical Bulletin, "Magnetic Water Treatment," 2001.

[6] A. Kotb and A. M. Abd El Aziz, "Scientific Investigations on the Claims of the Magnetic Water Conditioners," 2013.

[7] H. Banejad and E. Abdosalehi, "The Effect of Magnetic Field on Water Hardness Reducing," Thirteenth International Water Technology Conference, Hurghada, 2009, pp. 117-128.

[8] R. S. Abdel Tawab, M. A. A. Younes, A. M. Ibrahim and M. M. Abdle Aziz, "Testing Commercial Water Magnetizers: A Study of TDS and pH," Fifteenth International Water Technology Conference, Alexandria, 2011, pp. 146155.

[9] S. A. Ghauri and M. S. Ansari, "Increase of Water Viscosity under the Influence of Magnetic Field," Journal of Applied Physics, Vol. 100, No. 6, 2006, Article ID: 066101. doi:10.1063/1.2347702 